\title{
INTEGRATION AND AVAILIBILITY OF DATA - PARADIGMS AND APPLICATIONS
}

\author{
Robert PROKOPCZUK \\ Faculty of Management \\ Warsaw University of Technology, 02-524 Warszawa, Poland \\ email: R.Prokopczuk@wz.pw.edu.pl
}

\begin{abstract}
The problem of modern organization is not only information gathering but also its appropriate distribution within an organization. It is difficult to meet without appropriate computer based information system. The paper deals with making data available in computer based system for management purposes. There are discussed advantages and disadvantages of the Internet technologies from business process point of view.
\end{abstract}

Key words: information system, data sparing, Internet technologies, business process, system integration.

\section{Introduction}

One of the key challenges, in the knowledge based economy, is the ability to allow others to use gathered data. Differentiation of used forms and tools of data sharing is performed according to the data type. Dynamic development of Internet technologies creates new possibilities of cooperation.

Financial and organizational limitations, present in IT projects, make the traditional methods insufficient in current problem solving and analysis and designing of business IT systems. The critical limitations are [1]: project budget, task realization deadlines and system users' IT awareness. In terms of personal or economical data sharing, legal limitations have to be taken into consideration.

Informational needs of the users are not likely to be determined without performance of detailed analysis and the elaboration of the enterprise's IT system modernization project. The system should be created according to future tasks and not current operations. Elaboration of such system consists of $90 \%$ of organizational activities and only of $10 \%$ of IT activities [2]. Determination of the needs and requirements of users can prove difficult, even with the performance pf such detailed analysis, as users usually relate to the current situation. Adjustment of IT systems, which support the data integration and availability processes, to the dynamically changing needs of the organization in this scope is the condition of their usefulness.

\section{Informational system of the enterprise}

Current Business IT Systems are not created from scratch with the use of programming tools but rather through the adaptation of selected software to the needs and requirements of the users. Together wit the development of programming abilities the disproportion between the functionality of IT system and the functionality of the software, whose database was used to elaborate the system, increases. Concept of system functionality, in this article, is defined as what the system does, or should be doing, regardless to how it is doing it [3].

Informational system is the network of relations, whose centers are the elements of the organization and its environment that take active participation in data exchange and their relations describe the information exchange channels. However, in the scope where the data is processed with the use of computer hardware, it is treated as an IT system.

Functionality disproportion is connected with the mechanism inbuilt in the software that allows adjustment of the functionality of IT system to the needs of the enterprise. They can be divided into two groups according to the system functionality modification possibilities. First group consists of configuration tools, which are used to introduce the functionality settings defined in the software. Second group consists of 4GL languages, which allow defining new system functionalities [4].

Advanced adaptation mechanisms allow adjusting the system, to the needs of a user, at three levels. First level is serviced by the regional representative of the manufacturer, which introduces modifications that adjust the system to the specific regional conditionings. Second level is serviced by the IT system provider, usually partners responsible for the implementation of the system. 


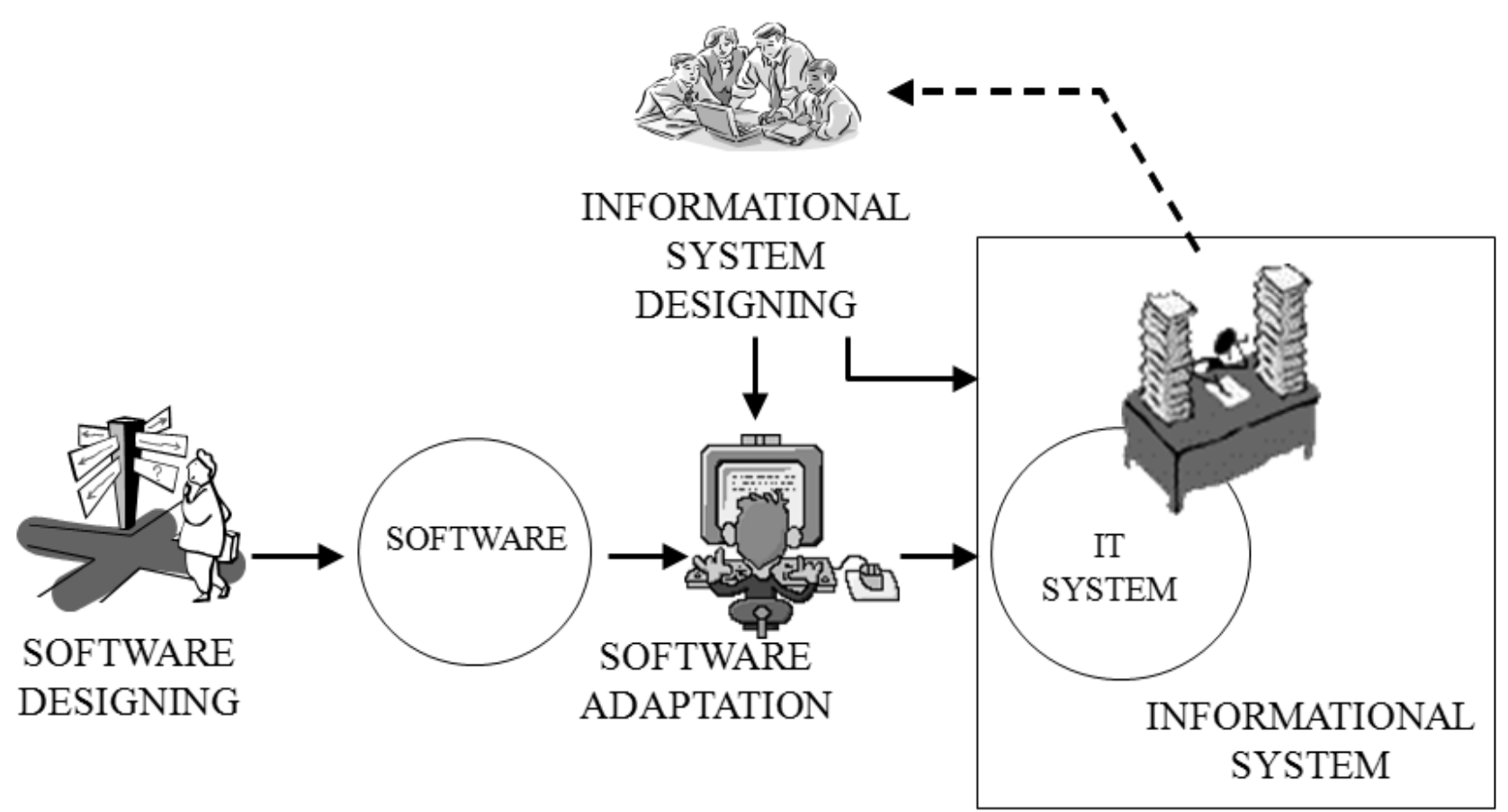

Figure 1. Functionality disproportion (source: self elaboration)

Moreover the system is equipped with solutions that allow the user to adjust the system, in certain degree, to individual preferences e.g. settings of the look and content of particular dialogue windows.

\section{$3 \quad$ Data sharing system}

Information is the data put in a context in the process of its interpretation, which can have statistical or analytical character.

Data is a grammatically defined symbol sequence. In the IT system it can be represented through bits, bytes, records, tables, files. In the semiotic aspect the interpretation can be realized in the syntactic (structural), semantic (significative) or pragmatic (utilitarian) aspect [2]. It is presented in the following example. The sentence below, according to the type of aspect, can be interpreted as true or false:

- computer turns off the user,

- user turns off the computer.

According to syntactic aspect both statements are true. All words included in the sentences are built of set grammatical symbols. However in the semantic aspect the first sentence is incorrect, because it makes no sense. Key to the interpretation is the knowledge about the surrounding reality.

Due to this knowledge one can evaluate the correctness of the relations between particular parts of information and bestow them with meaning. Giving meaning to the information is a human domain [5]. Basic features of information in the system approach are:

- actuality: compliant with the actual state, considered according to given situation,

- accessibility: possibility to access information in given time and place,

- confidentiality: limited access to the information according to the authorization level of the system user,

- possible to process: possibility to apply technical resources for the gathering, storing, processing and sharing of information,

- completeness: there is no need to use other sources in order to provide information useful for the user.

Criterion to distinguish information subset, necessary for management, from the information collection is the possibility to decrease the uncertainty of taken decisions as well as the organization activities [6].

Organizational resources availability is an example of such type of information. Information sharing sys- 
tem for management purposes is an informational system connected with the managerial information sharing system processes. In this elaboration the data sharing process is the collection of procedures and activities, which are used to realize business goals in the organization, as a part of a context determined with the organizational structure that defines roles and relations between them.

They can be realized through one or several organizations that have both formal and informal interactions. There are two types of processes in such systems:

- information gathering processes, which are responsible for gathering and introduction of the information to the sharing system,

- information access processes, which define the way the user is given the access to information.

Lack of direct succession of events between gathering and information access processes is typical. If considering the degree of interactivity as a criterion, one can perform a division of considered system types into ones with single-directional and double directional information flow.

Example of considered system type can be the conference room time-booking system for the needs of the didactic process. Limitation of the complexity of the system in the considered system type, into the elements necessary to understand the essence of the processes, was made in order to clarify the example

Figure 2 presents the conference room availability information gathering process. Availability plan is introduced into the system, which allows the users to check the availability of particular conference rooms.

Information gathering and access processes integration tool, in the scope of three-layer integration architecture (presentation, business logic and data layers) [7], is a database system. However, at the function integration level, the integration is realized through the use of CASE tools.

Using IT technologies allows limiting the interaction between a person, or people, sharing the information and its receivers.

There are systems, in which information sharing users take part in the data access process e.g. as experts that answer submitted inquiries. Implementation of such solutions aims at improvement of information sharing processes in order to make the information access more effective and clear.

It creates new possibilities in organizational activities with participants that are authorized for individual activities.

Data sharing systems can be divided into direct and indirect. In direct systems every inquiry has a relevant individual answer. However, such types of computerized systems, which provide the answer without help of a human, exist only in theory.

In practical applications one can find systems searching for experts who provide answers or, so called, artificial direct systems that are based on FAQ mechanisms (Frequently Asked Questions).

Functioning of indirect systems in based on knowledge base browsing and using of e.g. full-text search, identification of hierarchical classification. Assuming the level of interactivity as a criterion, it is possible to divide the systems into:

- single-direction data flow systems (passive data sharing) - realized on the basis of HTML technology. They allow the transferring of particular content to the user e.g. IT enterprise can share the information on the methodology of IT project realization. Shared information is of static nature,

- two-way-direction data flow systems (interactive data sharing) - allow the users to input data into the system e.g. in the conference-room availability system the user can input information about booking a certain room. In such systems the data is subjected to dynamic changes. Changing of shared information is related to their updating by the people who share particular information and creation of new information as a result of system user's activity (information receivers) connected with gathered piece of information.

Keeping the IT systems, which support data sharing processes, adjusted to the dynamically changing needs of the organization in the age of knowledge-based economy is a condition of the information usefulness.

One of the barriers of implementation of considered systems is the use of traditional technologies for designing dedicated IT systems. Therefore this is the reason for the elaboration of new designing technologies. 


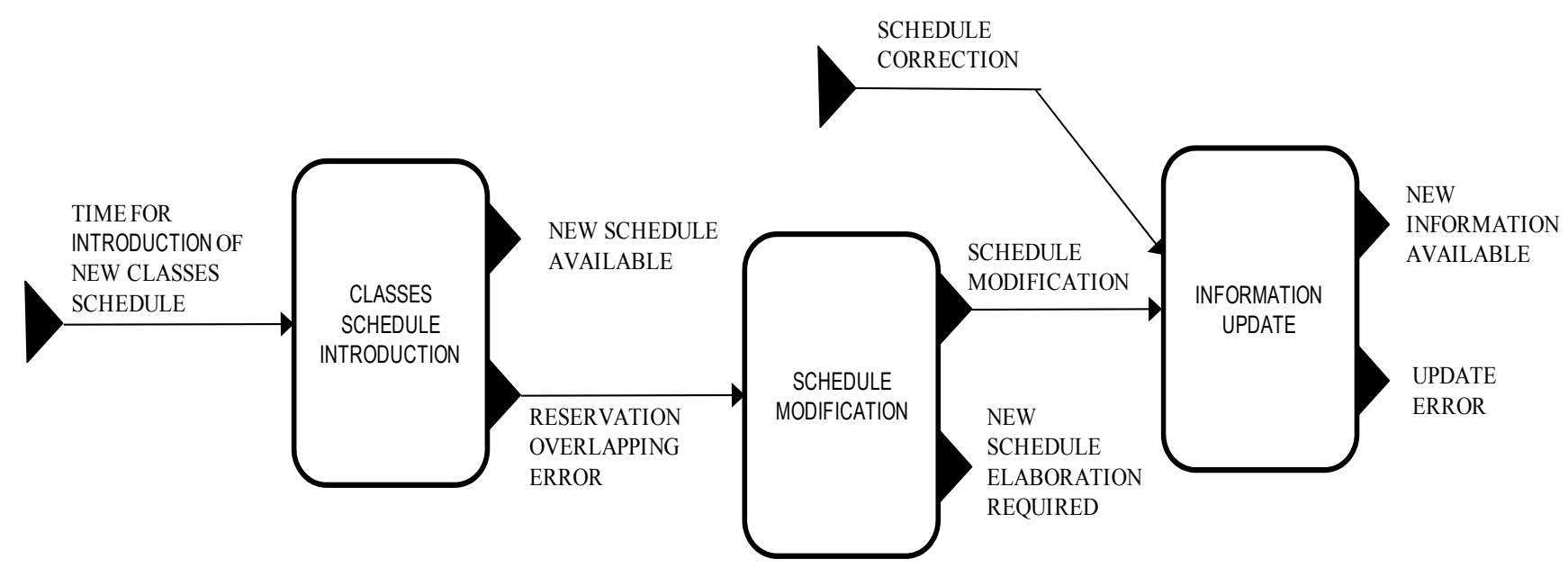

Figure 2. Conference-room availability information gathering process

Data sharing

Data sharing is the determination of data accessing rules and the process of their realization, which allows transactional data processing (in predicted time and completely finished) in the IT systems as well as access rules management, what assures safety and continuity of organization's activities. Data access can be realized with the use of traditional and modern tools, which should be selected according to the character of data sharing processes. Benefits connected with the implementation of modern technologies that support these processes are still not appreciated by small and medium enterprises. Major source of data exchange in such enterprises is still only the email.

There is a series of complex solutions for data sharing in the limited understanding of the concept, which is indicating that it is only a computer software program allowing data access. They allow the access to data recorded in databases and spreadsheets, their analysis and visualization based on a web service or access directly from within the traditional windowed application through special components.

In the organizational grasp of the problem one should look at the data sharing as a communication process between the person requiring specific data and a person or people that possess it. Three types of data sharing can be distinguished:

- read-only data,

- data subscription,

- data for selected users,

- data on demand.
Data access cannot be realized freely. One needs to take into consideration e.g. legal limitations: personal data protection, economical data sharing, public information access or civil legal contracts.

\section{Data sharing tools}

Everyone knows about the possibility to gather particular information in a telephone conversation. Development of modern information sharing tools results in the decreasing popularity of traditional communication means such as telephones.

Interactive dialogues between a human operator and computer are a novelty e.g. through self-service voice technologies based on the VoiceXML technology.

Table. 1. Benefits and challenges of telephone usage

\begin{tabular}{|c|c|}
\hline Benefits & Challenges \\
\hline $\begin{array}{l}\text { - Direct contact with } \\
\text { the information re- } \\
\text { ceiver }\end{array}$ & $\begin{array}{l}\text { - Necessity for people } \\
\text { to synchronize the } \\
\text { conversation in time }\end{array}$ \\
\hline
\end{tabular}

\section{$5.1 \quad$ SMS/MMS}

SMS (Short Message Service) is a method of sending text messages in GSM networks. It enables to send a 160 digit message to a given phone number. Sending longer messages is realized through division into several shorter messages. Messages are sent from a GSM telephone or from the Internet through SMS Gateway. 
If particular phone number is outside of reach, the message is recorded in message transferring centre and resent when given number becomes available. The successor of the SMS format is the MMS (Multimedia Message Service). It allows transferring messages that include multimedia content such as: text, graphics, sounds and video files.

Table 2. Benefits and challenges of SMS/MMS usage

\begin{tabular}{|c|c|}
\hline Benefits & \multicolumn{1}{|c|}{ Challenges } \\
\hline $\begin{array}{l}\text { Data access through } \\
\text { mobile phone }\end{array}$ & $\bullet \begin{array}{l}\text { Limitation of mes- } \\
\text { sage length to } 160 \\
\text { digits }\end{array}$ \\
\hline
\end{tabular}

\subsection{Internet mail}

Internet mail is a common and broadly used tool of information sharing. Conference websites publish the emails of the conference organizers. Potential conference participants contact the organizers through given address. Such type of communication deals with the problem of synchronization of interested parties in time.

Table 3. Benefits and challenges of email usage

\begin{tabular}{|l|l|}
\hline \multicolumn{1}{|c|}{ Benefits } & \multicolumn{1}{c|}{ Challenges } \\
\hline - $\begin{array}{l}\text { Easy exchange of } \\
\text { information }\end{array}$ & $\begin{array}{l}\text { Lack of confirmation } \\
\text { of information re- } \\
\text { ceiving from the re- } \\
\text { ceiver }\end{array}$ \\
$\begin{array}{l}\text { Possibility to deal } \\
\text { with a matter in suita- } \\
\text { ble time }\end{array}$ & $\begin{array}{l}\text { Limitations on the } \\
\text { size of sent files and } \\
\text { attachments }\end{array}$ \\
$\begin{array}{l}\text { Possibility to share } \\
\text { information too many } \\
\text { people at the same } \\
\text { time }\end{array}$ & \\
\hline
\end{tabular}

\section{$5.3 \quad$ Web service}

It is crucial for IT technologies to be most flexible and applicable in as many IT systems as possible, from the point of view of the technology providers. On the other hand in elaboration of particular system's prototype, only the final product and its usability are relevant.

Enterprises focus on selected technologies, which allow them to reach the highest possible competitiveness level. Figure 3 presents an example of web service architecture.

Website access requires use of a computer with internet browser and access. Rankings hosted at ranking.pl indicate that Microsoft Internet Explorer is the leading product in terms of internet browsers. Firefox and Opera internet browsers are becoming more and more popular with $30 \%$ of the market. Properly designed website needs to include the differences of functioning of these products. HTTP server is responsible for the resource access requests. Apache technologies are leaders in this product category. PHP script language is a common logical engine for such appliances. It is important to point out the ASP.NET technology as a leading technology for website design, which starts to exceed other technologies with its NET Framework engine in the 2.0 version.

Table 4. Benefits and challenges of Website usage

\begin{tabular}{|l|l|}
\hline \multicolumn{1}{|c|}{ Benefits } & \multicolumn{1}{|c|}{ Challenges } \\
\hline - $\begin{array}{l}\text { Information access is } \\
\text { possible with a com- } \\
\text { puter connected to the } \\
\text { internet }\end{array}$ & $\begin{array}{l}\text { Differences in the } \\
\text { functioning of inter- } \\
\text { net browsers } \\
\text { Replenishment of the } \\
\text { Pebsibility to transfer } \\
\text { multimedia content infor- } \\
\text { mation that is up-to- } \\
\text { Access to website } \\
\text { content through inter- } \\
\text { net browsers }\end{array}$ \\
\hline
\end{tabular}

\subsection{RSS Channels}

Information channels is the communicate headlines transferring technique based on the XML. Functioning of this system is based on RSS files (Really Simple Syndication) present at the server. Files are read by the RSS reader. User downloads the news titles together with their short descriptions and links to full messages placed in WWW websites. It is a simple way of reading and uploading information in the Internet that allows browsing through information form many sources (channels) in one application without the necessity to browse through many different websites. In order to use RSS one needs to install proper reader, which can be made as a plug-in to an internet browser or as a separate program. 


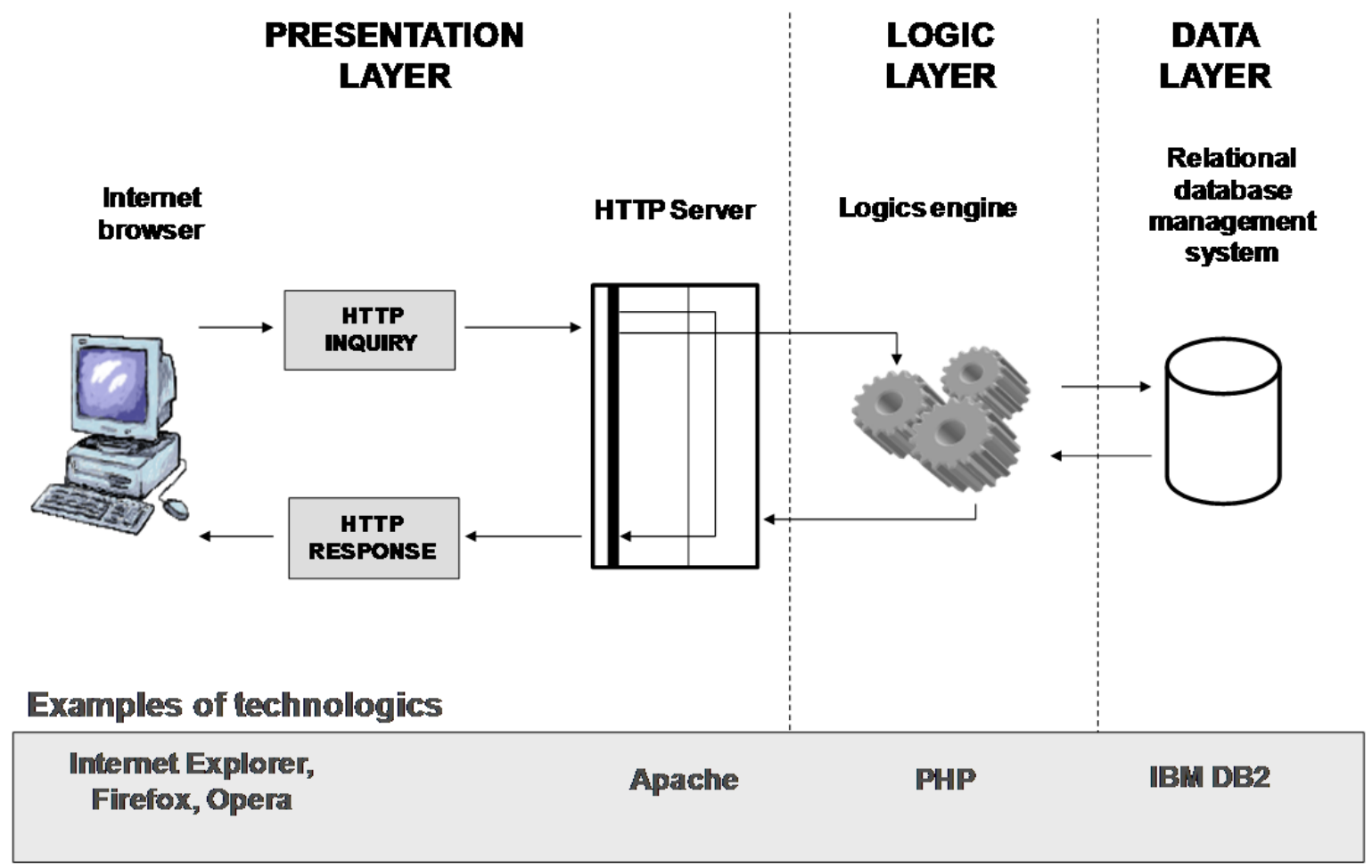

Figure 3. Example of website architecture from technical perspective (source: [11])

Internet Explorer browser, in version 7, has a built in RSS service. Atom is a new open standard developed by IETF (Internet Engineering Task Force).

Table 5. Benefits and challenges of RSS channels usage

\begin{tabular}{|l|l|}
\hline \multicolumn{1}{|c|}{ Benefits } & \multicolumn{1}{c|}{ Challenges } \\
\hline $\begin{array}{l}\text { Automatic creation of } \\
\text { information lists form } \\
\text { different information } \\
\text { sources }\end{array}$ & • $\begin{array}{l}\text { Scope of information } \\
\text { possible to access } \\
\text { through RSS }\end{array}$ \\
- $\begin{array}{l}\text { Internet connection } \\
\text { capacity saving } \\
\text { through downloading } \\
\text { of pure information }\end{array}$ & \\
\hline
\end{tabular}

\section{Use of internet technologies}

Using internet and telecommunication technologies requires certain knowledge and abilities. "Polish IT in European Union" report, published in 2003 and summing up work of the 3 Congress of Polish Information Technology [8], indicates that the realization of
IT endeavors depends, first and foremost, on the people involved in these activities and in a lesser degree on the used technology and IT tools.

There are several causes of IT project failure, apart from lack of software engineering usage, dependent on the customer:

- lack of composition of the future project in the business process of ordering enterprise or institution,

- lack of professionally prepared specification that corresponds to real needs (that is the basis for ordered project) or forging of the specification according o given designer as a result of corruptive activities,

- lack of proper knowledge and abilities to define assumptions and project receipt in the team,

- lack of knowledge and project, quality and risk management standards or even encouraging the customer to abandon them in order to reduce cost,

- lack of engagement and proper supervision fro the high management,

- selection of the designer on the basis of the lowest price and not the team skill evaluation and the functionality of offered solution, 
- lack of proper motivation and training of the system users.

The following failures were listed from the side of the designer:

- lack of ability to evaluate risk of performance of selected project,

- lack of responsibility for undertaking unrealistic tasks and acceptance of improperly prepared user requirements,

- price dumping or corruption activities used in order to win the bidding,

- lack of professional preparation of the team to realize the project (recruitment of the team after signing of the contract),

- lack of knowledge and standards in project management,

- lack of designing team work coordination abilities,

- lack of teamwork coordination abilities with the ordering team,

- lack of communication within the designing team and with the external environment,

- hiding the true level of project progress (hiding the obstacles and difficulties) from the management responsible for ordering the project,

- underestimation of doubts of common system users.
It was confirmed that the technical competences of young people with the use of IT tools, including internet, are usually very high. However, there still is a lack of common and effective model of text resources usage, provided by the new medium. Moreover, even the research on the model of such activities is not performed. Abilities to use the tele-informational tools by the Polish society are often high, although this phenomenon is not common. However, it should be said that the level of education in this field in Poland is not satisfactory.

According to the IT development strategy for the years 2004-2006 [9], by the Polish government, computer and internet skills are evaluated on the basis of: ability to write and print out a letter in a text editor, ability to send and receive electronic mail, ability to use internet browser and ability to search information in the internet. Such level of abilities is definitely insufficient for the creation of informational society. It is crucial to undertake actions that will speed up the IT competence improvement of Polish society in the scope of modern tele-communicational technologies usage. It is one of the goals of the Polish IT development strategy till 2013 [10]. It should be indicated that the lack of development of proper skills will result in lack of demand for electronic services and digital content, what can lead to the digital exclusion.
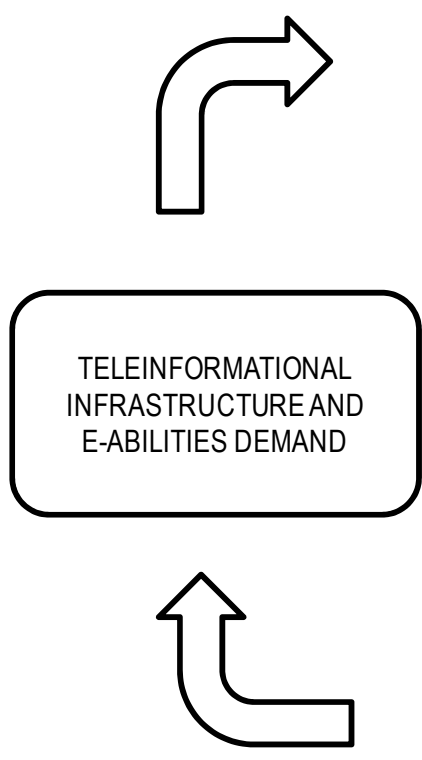
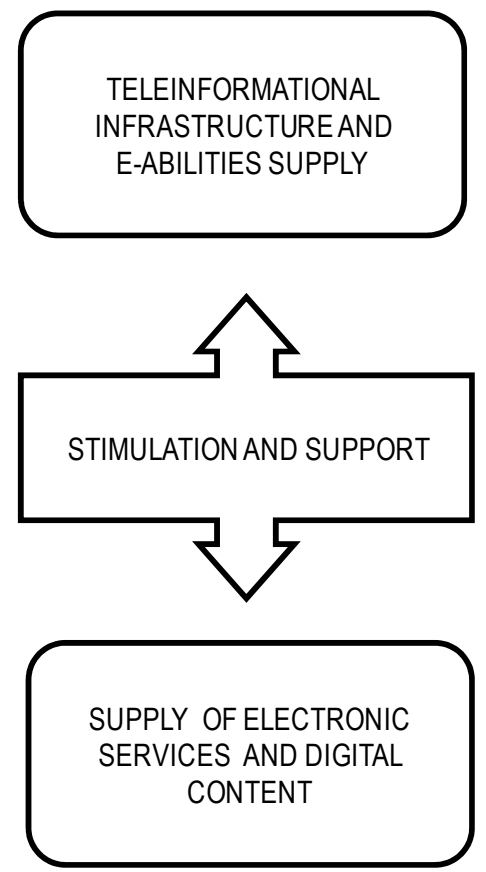

Figure 4. Areas of activity stimulating the IT development process (source: Directed strategy of IT development in Poland to 2013) 
In 2007 the Pew Internet \& American Life Project performed a research in the American market and published the results in a report "Typology of IT and telecommunication technology users" [12]. It concerns, among others, the sharing of private content in the web, posting comments to news published in the internet, creation of websites or downloading the content from the Internet.

The result revealed that sharing copyrighted content in the Internet is not common. It is important to point out that this phenomenon varies in different groups. Report creators divided IT and telecommunication technology users in the following groups:

- Group 1: contributing to $8 \%$ of researched population is the most active group of the internet society,

- Group 2: contributing to $7 \%$ of researched population are the people using internet to connect with others and access internet content,

- Group 3: contributing to $8 \%$ of researched population are people who have experience with internet technologies,
- Group 4: contributing to $9 \%$ of researched population are people using internet technology at work and at home, usually to increase personal productivity,

- Group 5: contributing to $10 \%$ of researched population are people who actively use mobile equipment and facilities provided by application designed for such hardware, although these people do not connect their personal productivity increase with the use of such equipment,

- Group 6: contributing to $9 \%$ of researched population are people investing in IT and telecommunication technologies but who are not able to use such technologies,

- Group 7: contributing to $8 \%$ of researched population are people who posses only few devices allowing to use IT and telecommunication solutions but feeling competent using such applications and would make more use of such facilities if provided access to such technologies,

Table 1. List of internet users' activity in the scope of personal content sharing (source: [12])

\begin{tabular}{|c|c|c|c|c|c|c|c|c|c|}
\hline & $\begin{array}{l}\vec{s} \\
\overline{0} \\
\text { 峁 }\end{array}$ & 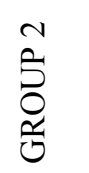 & 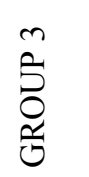 & 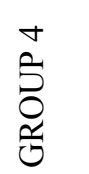 & 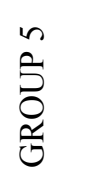 & 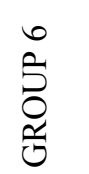 & 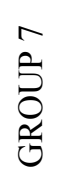 & $\begin{array}{l}\infty \\
\text { S. } \\
0 \\
\text { 今. }\end{array}$ & 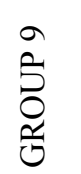 \\
\hline $\begin{array}{l}\text { Sharing the effects of per- } \\
\text { sonal work in the net }\end{array}$ & $55 \%$ & $38 \%$ & $20 \%$ & $18 \%$ & $14 \%$ & $12 \%$ & $9 \%$ & $4 \%$ & $4 \%$ \\
\hline $\begin{array}{l}\text { Posting comments to the } \\
\text { information published in the } \\
\text { net }\end{array}$ & $55 \%$ & $39 \%$ & $22 \%$ & $12 \%$ & $0 \%$ & $8 \%$ & $8 \%$ & $4 \%$ & $3 \%$ \\
\hline $\begin{array}{l}\text { Creation of websites for } \\
\text { personal use }\end{array}$ & $45 \%$ & $24 \%$ & $14 \%$ & $12 \%$ & $6 \%$ & $6 \%$ & $2 \%$ & $1 \%$ & $2 \%$ \\
\hline $\begin{array}{l}\text { Creation of commercial } \\
\text { websites }\end{array}$ & $40 \%$ & $17 \%$ & $13 \%$ & $9 \%$ & $8 \%$ & $4 \%$ & $4 \%$ & $1 \%$ & $2 \%$ \\
\hline $\begin{array}{l}\text { Downloading of internet } \\
\text { content for personal use }\end{array}$ & $30 \%$ & $19 \%$ & $10 \%$ & $8 \%$ & $4 \%$ & $4 \%$ & $2 \%$ & $3 \%$ & $2 \%$ \\
\hline $\begin{array}{l}\text { Sending and receiving SMS } \\
\text { messages in mobile phones }\end{array}$ & $93 \%$ & $49 \%$ & $36 \%$ & $42 \%$ & $94 \%$ & $19 \%$ & $14 \%$ & $12 \%$ & $12 \%$ \\
\hline $\begin{array}{l}\text { Sending text messages } \\
\text { through internet communica- } \\
\text { tors }\end{array}$ & $73 \%$ & $57 \%$ & $45 \%$ & $38 \%$ & $47 \%$ & $25 \%$ & $18 \%$ & $16 \%$ & $16 \%$ \\
\hline $\begin{array}{l}\text { Paying for access or down- } \\
\text { loading of digital content }\end{array}$ & $50 \%$ & $46 \%$ & $26 \%$ & $20 \%$ & $23 \%$ & $13 \%$ & $9 \%$ & $5 \%$ & $5 \%$ \\
\hline
\end{tabular}


- Group 8: contributing to $15 \%$ of researched population are people with basic access to informational technologies nut using it occasionally and not treating it as an important element of their lives,

- Group 9: contributing to $11 \%$ of researched population are people who do not see the benefits of access and usage of IT and telecommunication technologies,

- Group 10: contributing to $15 \%$ of researched population are people without access to modern IT networks.

Over $70 \%$ of respondents claimed that modern IT technologies allow them to be more accessible to others. Almost $80 \%$ of respondents feel that these technologies have more potential than currently used. Half of the respondents indicated that they need training in the scope of uses of modern technologies. Table above collects the combination of internet and other activity for particular researched groups.

\section{$7 \quad$ Business processes categories}

Possibility to support business processes and especially their automation through the use of IT and telecommunication technologies are strictly connected with their character. Process support with IT solutions can be divided according to their possibilities into the processes oriented at: integration, human or content. Basic characteristics and examples of processes typical for particular categories are collected in the table below.

Implementation of IT tools supporting different process classes requires flexible infrastructure. Other solutions should be used in case of fully automated systems, in which the role of operator is limited to the introduction of input data such as e.g. customer order or granting a loan. Determination of process class is critical in order to select the elaboration method that has the biggest chances of success.

Table 2. Business processes categories

(source: elaborated on the basis of Exploring key facts about business process management with IBM WebSphere software [13])

\begin{tabular}{|l|ll|ll|}
\hline \multicolumn{1}{|c|}{$\begin{array}{c}\text { Process } \\
\text { categories }\end{array}$} & \multicolumn{1}{c|}{ Basic characteristics } & \multicolumn{1}{c|}{$\begin{array}{c}\text { Examples } \\
\text { of typical processes }\end{array}$} \\
\hline $\begin{array}{l}\text { Integration } \\
\text { oriented pro- } \\
\text { cesses }\end{array}$ & $\bullet$ & $\begin{array}{l}\text { Fully automated processes } \\
\text { Usually with integration of the } \\
\text { person servicing the exceptions } \\
\text { or taking decisions }\end{array}$ & $\begin{array}{l}\text { Order realization } \\
\text { Provision calculating } \\
\text { system }\end{array}$ \\
\hline $\begin{array}{l}\text { Human orient- } \\
\text { ed processes }\end{array}$ & $\bullet$ & $\begin{array}{l}\text { Human work based processes } \\
\text { Decisions made by human }\end{array}$ & $\begin{array}{l}\text { Granting loans } \\
\text { Human-human interaction }\end{array}$ & $\begin{array}{l}\text { Purchasing products } \\
\text { and services }\end{array}$ \\
\hline $\begin{array}{l}\text { Content orient- } \\
\text { ed processes }\end{array}$ & $\bullet \begin{array}{l}\text { Tutomatic tasks frequent ap- } \\
\text { pearance }\end{array}$ & $\begin{array}{l}\text { Tent interpretation by human } \\
\text { Weak connection between the } \\
\text { documents and the process } \\
\text { Process controlled by the status } \\
\text { of works over a document }\end{array}$ & $\begin{array}{l}\text { Sending and processing } \\
\text { of documents or mes- } \\
\text { sages, } \\
\text { Browsing and } \\
\text { ceptance of documents }\end{array}$ \\
\hline
\end{tabular}




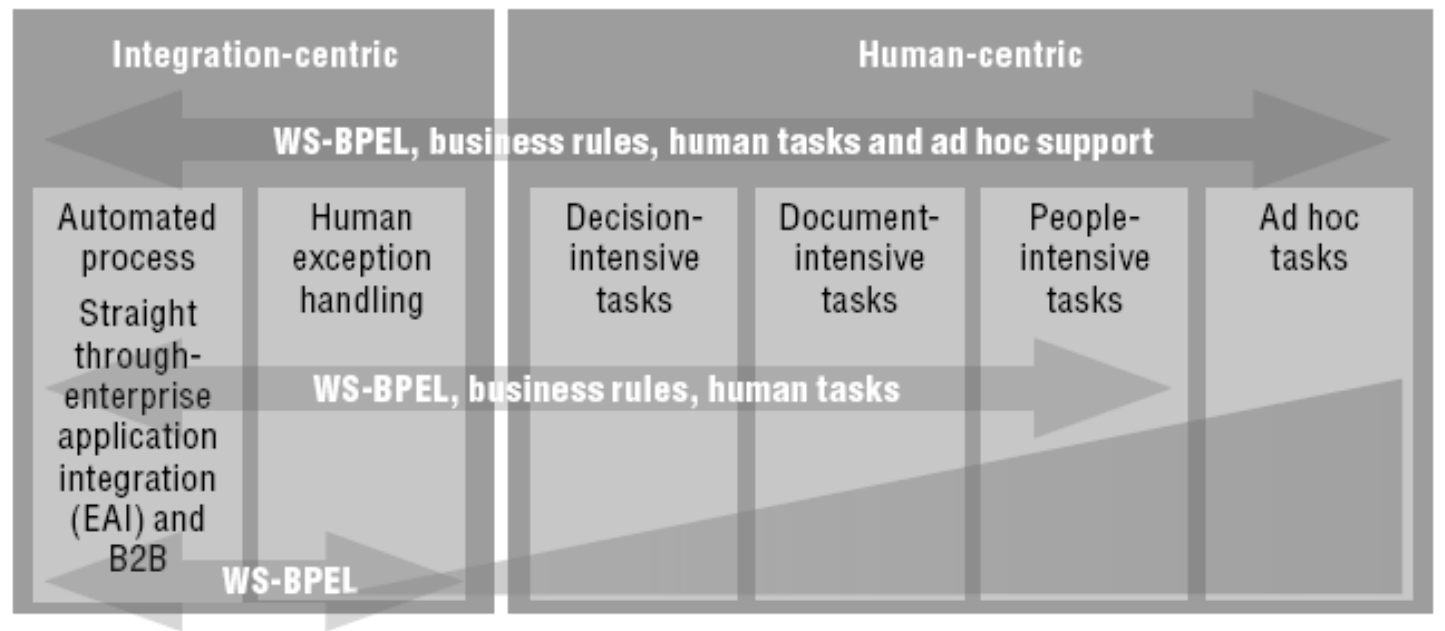

\section{Integration between applications \\ Predefined process interactions Unattended activities and automated tasks}

Mix of human interaction with process automation
Automation between people Human tasks and related content Ad hoc collaboration

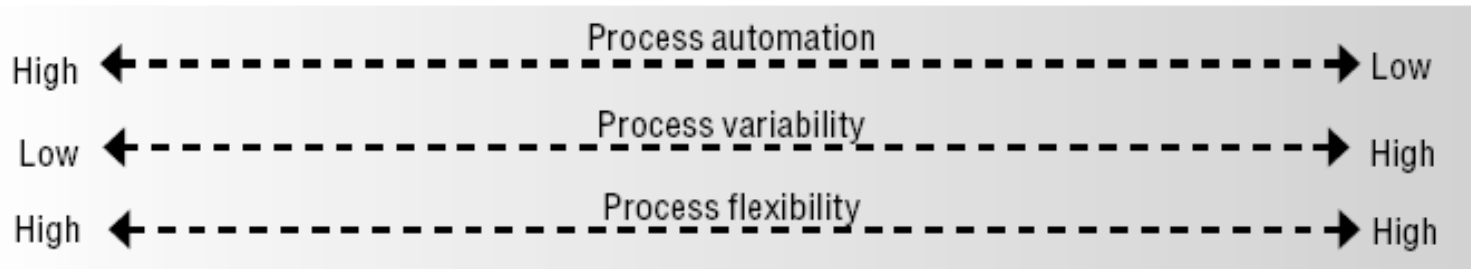

Figure 5. Spectrum of BPM scenarios using WebSphere Process Server (source: Exploring key facts about business process management with IBM WebSphere software)

\section{Integration oriented processes}

Fluent integration and the ability of automatic data interchange between the tasks realized by the IT system and the ones in the control of a human operator are characteristic for this type of processes. Firstly they connect system applications and services into one entity that supports reaching of business goals. Currently there are few IT solutions, which can help to solve such types of business issues. Most of the processes oriented towards integration requires human interaction in the area of exception handling and key decision making.

\section{$9 \quad$ Human oriented processes}

Human oriented processes connect the activities of organization's participants, realizing particular tasks, into one entity. The way the IT tools allow to cooperate is crucial for the process development effect, with the assurance of full transactional nature of the process. Quick and easy particular task realization progress data access is required, what implies the necessity to equip the IT systems with a user friendly interface. Possibility to sort and set priorities to particular tasks and assign particular human resources is required. Many human oriented processes require the possibility to integrate different systems is required from the start of the system elaboration or in terms of its development in order to increase the automation or effectiveness of work.

\section{Content oriented processes}

Generality of document content oriented processes requires a significant engagement of a person who can interpret the data. There are dynamic changes in this area, due to the continuing process of replacement of paper documents with electronic documents and forms. 


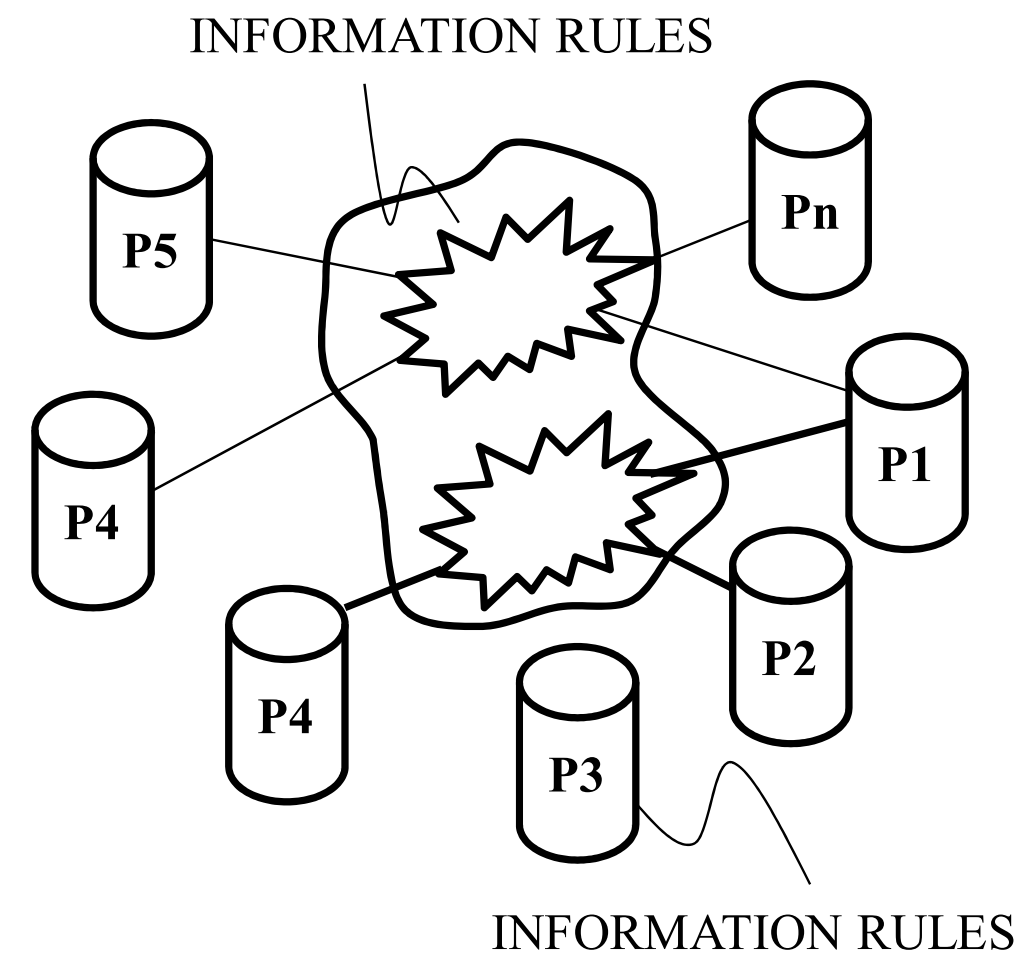

Figure 6. Integration of IT processes (source: self elaboration)

\section{Data integration and sharing processes}

One of the basic assumptions of extreme programming is that it is more profitable to create small subsystems and then integrate them, rather than elaborate large and complex systems. Two aspects are present here. Fist one is the integration of processes that were identified at the stage of system creation and their integration level is determined.

Logical data model is created for particular subsystems and next the models are integrated before starting of the creation of application at customer side. There is, so called, data structure freezing, in the area of mutual data, which is later modified only due to significant reasons. Such approach is inconvenient and the desired solution is the possibility to modify data structure in any moment of system creation process.

Key to reaching of desired flexibility in the scope of data structure is the use of system architecture that favors such modifications and approach based on prototyping, where the prototype is created as a result of model transformation into the source code and SQL scrip that defines the database. Having the $\mathrm{N}$ version of the database and the desired structure $(\mathrm{N}+1$ version) it is possible to define the transformation process from the $\mathrm{N}$ state to the $\mathrm{N}+1$ state. Performance of such activities does not usually cause technical problems. In some cases such as e.g. transformation of a discount for a single product to a discount for a group of products has an irreversible character so that it is not possible to return from the $\mathrm{N}+1$ state to the $\mathrm{N}$ state.

Transformation of the application form the customer side for it to use the new data structure is much more difficult. Sometimes the scope of the modification is so considerable that the only efficient solution, form the perspective of the customer and the provider, is to elaborate the customer application form the start. With the approach based on generation of new source code from the system model one is equipped with a tool to solve such implementation issues methodically. Used model structure should allow the determination of the scope of necessary modifications in relation to the changes in data structure and its processing. Proposition of such type of structure is presented in the following chapter.

Data integration is the connection of format and subject heterogeneous data collections as well as data storages in a way to assure their semiotic (syntax, semantic and 
pragmatic) effective sharing. There is no universal solution for enterprise IT process integration issues. However it is certain that the enterprise will not be able to undertake effective decisions without effective activities. It is necessary to determine its scope.

Maximal process integration results in stiffening of their adjustment to new business conditions. Such situation usually takes place when dealing with integrated IT system that is supporting the processes. Low integration level integrates in the decrease of the information system efficiency. Following forms of integration are popular:

- system integration - deals with communication between systems,

- application integration - deals with application cooperation,

- business integration - deals with economical processes integration.
Integration precedes the data sharing in IT systems. It is possible to select one of two solutions: integration broker or integration platform. The lack of integration strategy results in, so called, integration web. Integration processes and data sharing are cause-related activities that are aimed at data gathering and allowing access to the data to authorized users. It can be realized through one or several organizations, which have both formal and informal interactions. The basic elements are: people sharing the data, data sources, data receivers, rules and access authorization, data sharing process integration rules and regulations.

If taking the integration level as a criterion it is possible to perform considered division of these processes into single-direction and two-way-direction data flow.

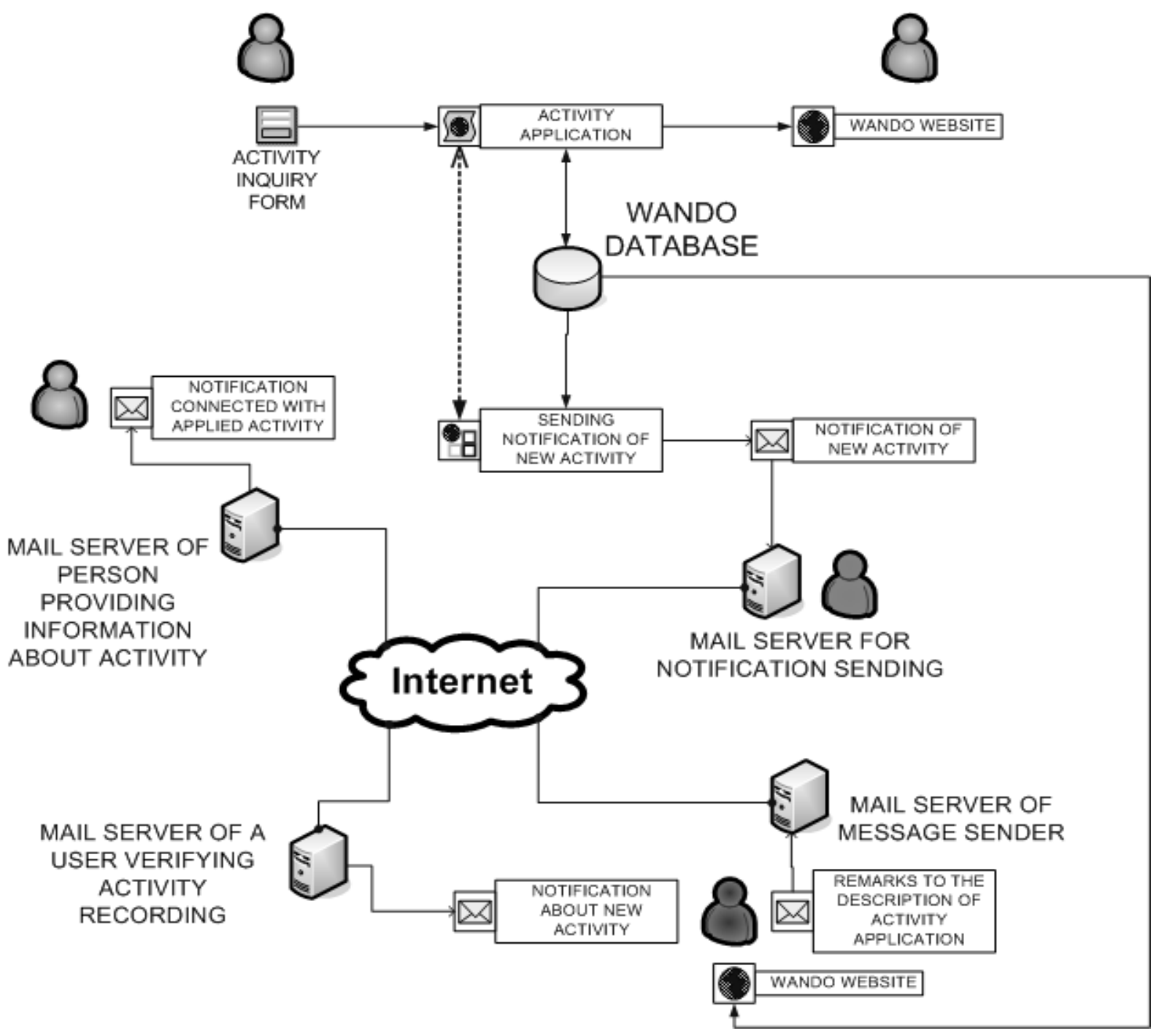

Figure 7. Example of integration architecture with the use of electronic mail (source: self elaboration) 
Database system is the integration tool, for data gathering and access processes, in the take of three-layer integration architecture (presentation, business logic and data layers) [14], at the application integration level. CASE tools are used to realize the integration at the level of function integration.

If taking the type of possessed data as a criterion it is possible to divide the data sharing processes into direct and indirect. In direct systems every inquiry has a related individual answer. Totally computerized system that would be able to provide such answer without the help of a human being exists only in theory. In practical applications one can find systems searching for experts who provide answers or, so called, artificial direct systems that are based on FAQ mechanisms (Frequently Asked Questions). Functioning of indirect processes is based on knowledge base browsing with the use of e.g. full text search, indexing or hierarchical classification.

When speaking of integration processes and data sharing it is impossible not to consider the IT system architecture. It is important for the architecture to be flexible and allow creating different types of software from the perspective of the technology provider, because it expands the number of potential customers. However from the perspective of the creation of a particular system only the final product is relevant. Performed research indicates that particular providers of IT systems focus on selected technologies, which allow creating the final product with the highest possible usage value. Enterprises decide to use certain database systems, which will cooperate with their product, due to economical factors.

Figure 7 presents an example of integration architecture for the creation of databases dealing with professional activity of scientific personnel. This architecture supports the human oriented processes with the use of electronic mail. Main advantages of such approach are the relatively low technological requirements. Main disadvantage is the relatively high work and time consumption as well as the result relating on the people engaged in the processes to a considerable degree.

\section{Data transformation}

Transformation is the data processing process that does not modify the source data - in typical data processing processes it is common to transform the data collection from one state to the other, without the change in data structure. In the transformation process data is collected from the source, processed and transferred to the destination structure. Practically there usually is a need for manual completion of target data structure. Data structure transformation with small modifications of their information scope is an activity that takes place in:

- database structure change - takes place during modifications of exploited software or migration to other systems,

- linking of not physically connected subsystems with common tables - supporting of enterprise activities with dedicated solutions might require it systems from different suppliers. therefore it is essential to elaborate a common interface between these systems,

- data transformation form logical data structure to the physical table implementation - realized with importing or exporting of the data from or to the system,

- introduction of new data to the database - differences between the data presented to the user and the logical data model in the database can be present due to the data model normalization process. Such situation might be encountered during the increase of user interface effectiveness (defined as the amount of data that the user is able to introduce with particular user interface organization) and organization of such interface in a non-normalized manner. Normalization is performed automatically. Possibility to transform non-normalized data into normalized data is a necessary condition in such type of activities.

Relational database or an external data set can be the source data collection. Relational database is a data structure collection, used for data organization and storing. Basic data unit in the relational data model is the atom, indivisible, e.g. document metrics. Atom data sets of the same type are defined as domains. Domains are organized into tables in a way to minimize the data redundancy according to data normalization requirements. Relations (integration reference) are defined as presence of particular data in the table that is dependent on the content of another table. Every table should be equipped with a primary key that allows unambiguous identification of a particular table row (entity integration). SQL (Structured Query Language) language is usually the standard interface for such applications. 


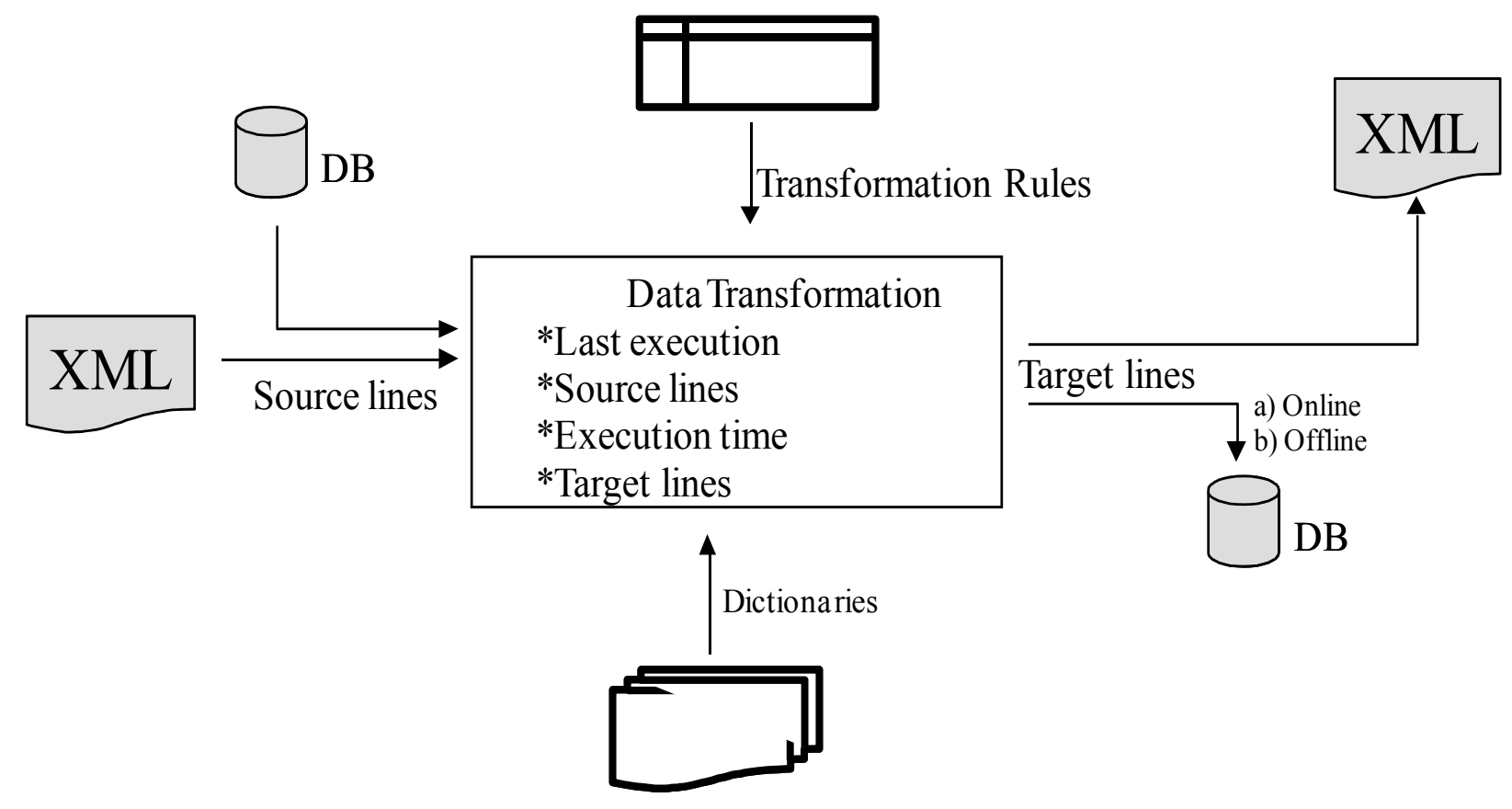

Figure 8. Data transformation (source: self elaboration)

It should be noted that all data collections, which cannot be processed together with the database with the use of SQL language, are the external data sources.

Currently the data recording standard in such collections is the XML [http://www.xml.org/]. Such data collections are used for the data interchange between

different systems. Dictionary data can be used in the process of transformation. There are two areas of their usage. First one is the verification of data correctness in selected data areas. Second one is the change of domain set that is included in data structures. Data mapping rules, from the input to final data structure, are determined with data transformation rules. Flexibility of the defining process decides about the practical possibilities of the data transformation process.

In the first step the data is taken from the input and transferred to a spreadsheet layout with a homogenous column structure. Input column mapping into output data takes place $\mathrm{n}$ the second step. In practice data acquiring requires preparation of several perspectives.

Preliminary data processing according to their transformation process is realized at the perspective level.Directing the data towards the exit is performed by dedicated mechanisms. Logical variable values, which are the switches for the data transferring performance to particular exit, are set in the first step. After the finishing if the data directing for selected input line it is possible to return to data transformation and another redirection of data collection (variables at collections).

\section{Relation models}

Relation model describes the universal solutions possible multiple usage and the correctness of solutions included in it must be documented. They are the basis for creation of dedicated model and characterize with general usability, adaptability for particular conditions and consistence and transferability [15]. Relation models are defined at a certain level of abstraction. They do not provide concrete IT solution but are rather an inspiration for one. Such model can be created on the basis of an existing or planned business process. Main partial elements of such model are:

- graphical representation of activities and relations between them together with additional data. The basic element of activity representation is the task that is at the lowest level of work at presented diagram. Connections are represented in the diagram as arrows connecting particular activities,

- business positions - all kinds of documents, products, parts, components, minerals or chemical compounds processed in the activities,

- resources and their consumption as well as their assigning, with consumption rate, to particular tasks. 
Process flow diagram is supplemented with starting points (indicating the beginning of the process), finishing points (indicating the end of the process) and flow finishing points (indicating the end of a certain flow).

If the flow reaches the finishing point during the performance $\mathrm{pf}$ the process it is immediately stopped, even if other performed flows are present in the process for the time being. However, flow finishing points is just a visual marker inside the process and indicates the end of a certain flow.

Process flow path can consist of many alternative and parallel branches. In case of alternative ramification, the flow is realized through one of the available branches, usually selected in a decision process.

The following objects are used in the division of the process into alternative and parallel realization paths:

- decisions: process elements that allow division of the flow path into alternative branches,

- ramifications: process elements that allow division of the flow path into parallel branches,

- merges: process elements that allow merging of the alternative branches,

- connectors: process elements that allow connection of the parallel branches.

In case of complex processes that are not possible to identify with one level of abstraction, sub-processes, which are a separated part of the main business process represented at certain abstraction level as a single element, are used.

All processes can have any layout of the elements, which does not bring limitations, placed in the diagram. Example of a process with a free type of layout is presented in the Figure 9.

Process course layout is an alternative for such process layout. In the course layout the process flow is presented in a way to enable focusing of the role, resource, organizational units, places and classifier values usage of the activities as part of the flow.

Visualization of process courses helps to identify the unnecessary exchanges between the elements in different rows. This also leads to the elimination of bottlenecks and redundancy.

From the perspective of process analysis it is crucial to determine the distribution of selection of particular flow branches. For example is receiving an inquiry from an internet user generates cost equal to 10 PLN and receiving an inquiry in the paper form generates the cost of 50PLN - both for the distribution in the figure above and 100 performances the total cost will equal 3 000PLN.

It is obvious that if the distribution is altered and $80 \%$ of inquiries are submitted via internet, we will reduce the cost to the level of 1800 PLN.

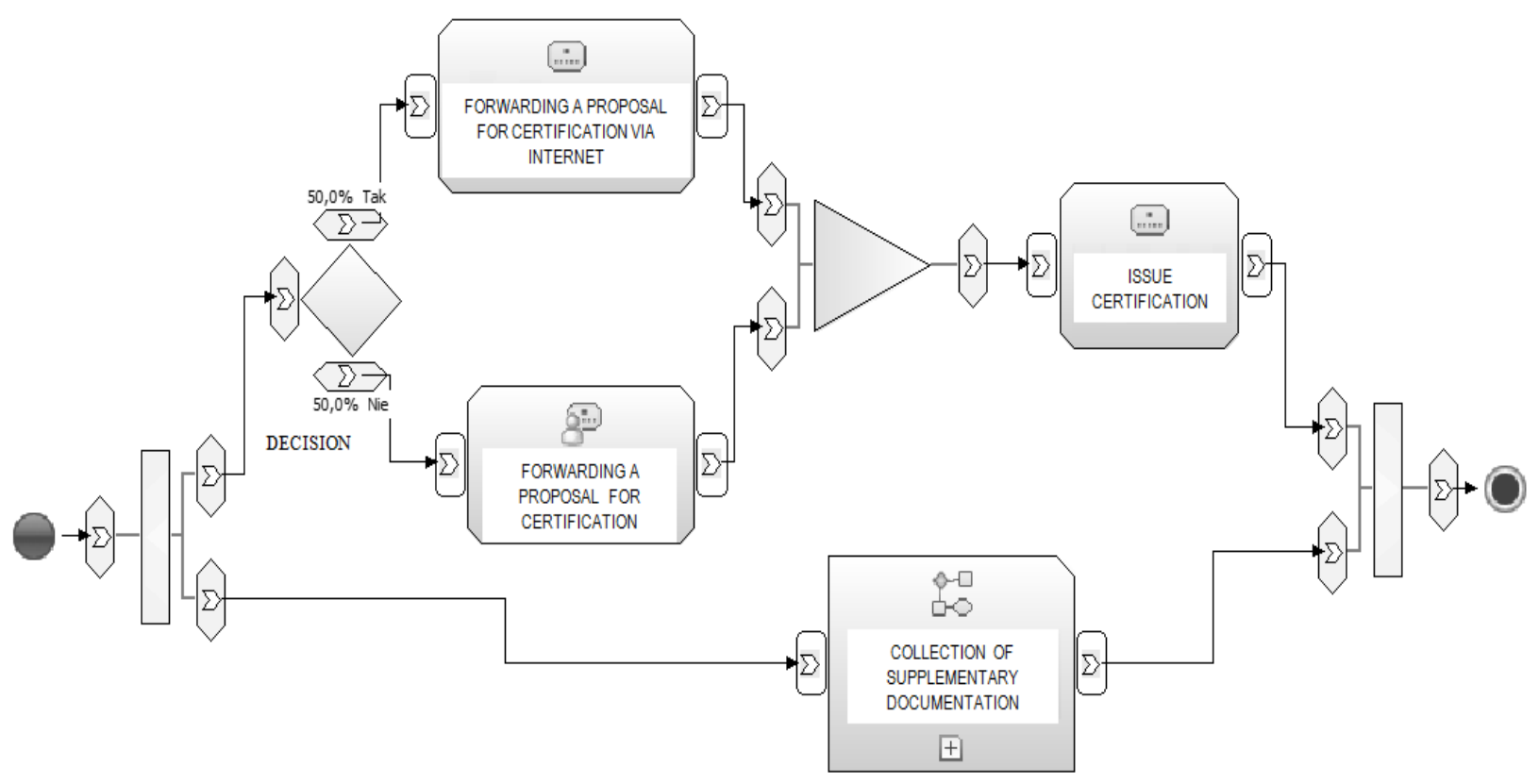

Figure 9. Example of process flow model (source: self elaboration) 


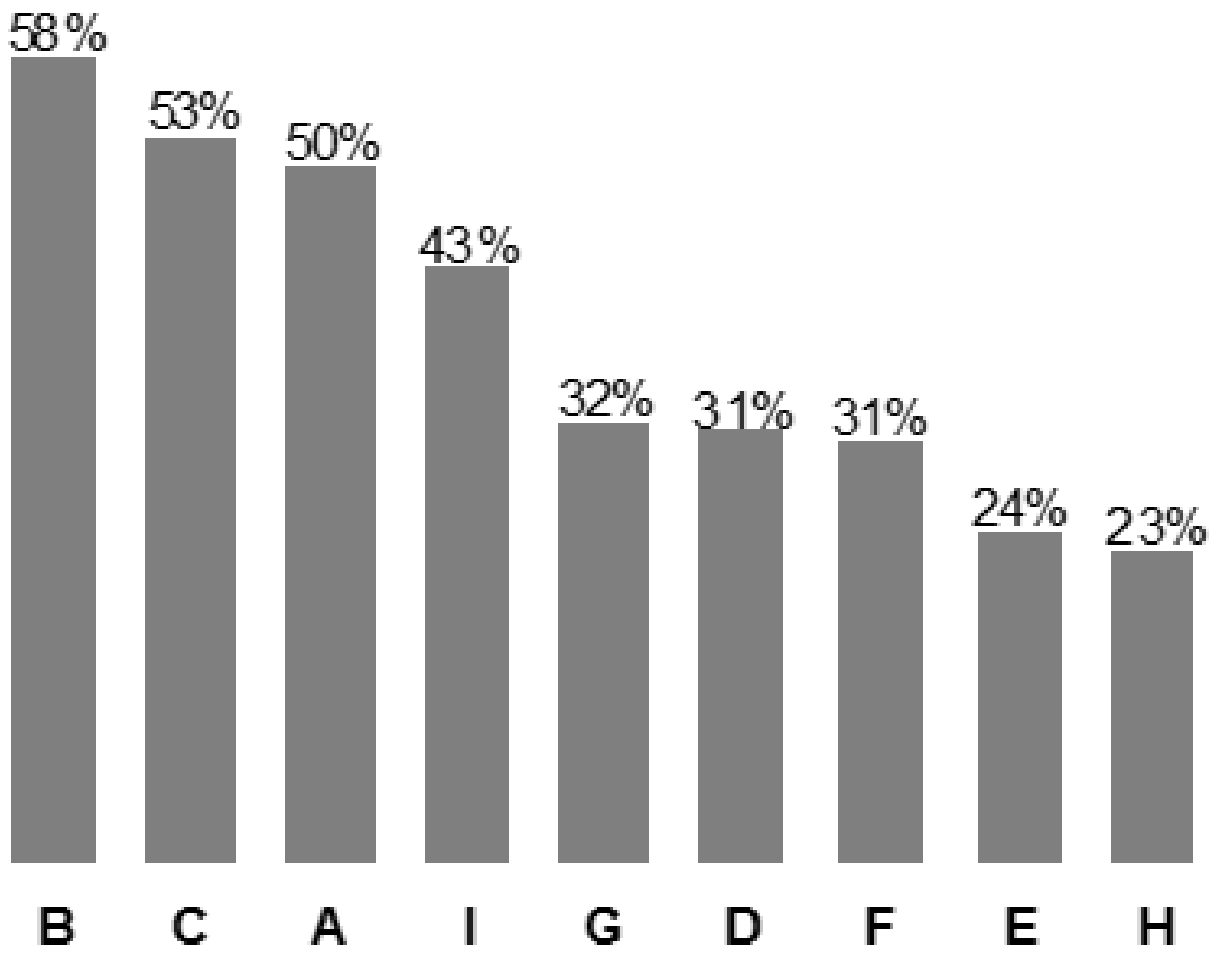

Legend:
A. information on current events (expos, conferences, exhibitions, branch events),
B. current information (news),
C. articles,
D. guidebooks, lexicons,
E. case studies,
F. questionnaire results,
G. branch curiosities,
H. book reviews,
I. links to related pages.

Figure 10. Questionnaire results in the scope of knowledge base components usefulness (source: www.e-marketing.pllbadanialankieta.php.htm)

Relational model is a specification of all important process elements and their relations, defining the rules of its functioning, created as a result of many project analyses (relating to identical or similar issues), applicable as a tool that aids problem solving in relation to the problem it was elaborated. It is based on a certain number of consolidated concepts and experience from earlier projects. Creation of such model requires methodology and software aiding the knowledge synthesis process.

Sharing process model should answer the following questions:

- what scope of dynamically modified data will be published in the website, 
- what actions are necessary for the realization in order to assure the topicality of provided data,

- what should the system architecture be like in order to support data sharing.

\section{Internet as a source of information}

One of the main activities undertaken to create the informational society is the popularization of internet access through the telecommunication infrastructure development.

As a result a constantly growing number of internet users can be noted. Imperfection of the internet knowledge base organization is a major limitation for the users, preventing them from gaining desired information. Internet and its content is discovered by the users pragmatically. Creation of individual internet and available content usage models is a result of such approach.

Attempt to capture the qualitative aspects of internet usage was undertaken by the www.e-marketing.pl website. Around $75 \%$ of website receivers have over one year of experience with the use of internet, what can be deducted from the data published at the website. This factor definitely influences the results of performed questionnaires.

Interned usage model formulated on the basis of such results is relating to the quality of the usage of this tool by the society that contributes to the creation of informational society. Majority of the content available in the internet decides about its attractiveness.

Everyone can find some piece of information that is of value to her or him. Therefore there is no single model of usage for this technology. Around 180 respondents have answered to this questionnaire.

Over a half of the respondents indicated articles and current news as useful component of a knowledge base. Less than $25 \%$ of respondents see case studies and book reviews as an irrelevant component of knowledge base. Content searched in the interned is different for particular users.

Effective usage of internet resources is limited by a lack of efficient cataloguing system. Increasing number of indexing servers (browsers) complicates even more the sorting of information. It leads not only to a decision - how to search?, but also - where to search? In this area the questionnaire had over 300 responses.
Imperfection of the internet knowledge base organization is a major limitation for its users.

Various browsing systems limit these issues to a certain level. However, the biggest weakness of such websites is providing links to obsolete and non-existing websites, several links to the same address and results not compliant with the inquiry. This is a result of an open nature of internet so the disturbances pointed out by the users should by treated as unfavorable but inevitable.

\section{Summary}

Data sharing and integration issues in management systems are always present, where there is an information exchange process between groups of people. Maintenance of channels' availability and topicality is becoming more difficult with the growing number of channels. However, implementation of telecommunication technologies allows dealing with such issues. One should bear in mind that mere elaboration of the solution is not sufficient.

Business processes designing is necessary. It is definitely connected with the redesigning of the processes currently existing in an organization.

Using modern IT technologies is not the only success factor - change of organizational culture is crucial. Organizational participants need to take active part in the process and be willing to share data with other participants.

Currently there is no model in the web that would allow sharing the effects of one's work and gain benefits form this process. It is necessary to undertake research leading to the determination of the influence of particular technology on the effectiveness of processes in the enterprise.

The main issue to resolve is the identification of possible telecommunication solutions application for the prototypes of IT solutions that are to be implemented.

\section{References}

[1] Górski J. - Inżynieria oprogramowania $w$ projektowaniu oprogramowania. MIKOM, Warszawa 2000.

[2] Krupa T. - Projektowanie strategii informatyzacji [in] Przedsiębiorstwo w procesie globalizacji, (Krupa T. ed.), WNT, Warszawa 2001, pp. 207224. 
[3] Barker R., Longman C. - Case* Metod ${ }^{S M}$ Modelowanie funkcji i procesów. WNT, Warszawa 1996.

[4] Avison D., Shah H. - The Information Systems Development Life Cycle: A First Course in Information Systems. McGraw-Hill, England 1997.

[5] Oleński J. - Ekonomika informacji. Metody. PWE, Warszawa 2003.

[6] Kisielnicki J., Sroka H. - Systemy informacyjne biznesu. Placet, Warszawa 2001.

[7] Krupa T., Ostrowska T. - Strategy of Informatization and Development of Database in Business Organizations [in] New challenges and old problems in enterprise management (ed. T. Krupa). WNT 2002.

[8] Polska informatyka w Unii Europejskiej. Raport z 3 Kongresu Informatyki Polskiej, Warszawa 2003.

[9] Strategia informatyzacji Rzeczypospolitej Polskiej ePolska na lata 2004-2006. Ministerstwo Nauki i Informatyzacji, Warszawa 2003.
[10] Strategia kierunkowa rozwoju informatyzacji Polski do roku 2013 oraz perspektywiczna prognoza transformacji spoleczeństwa informacyjnego do roku 2020. Ministerstwo Nauki i Informatyzacji, Warszawa 2005.

[11] Chen W. J., Kirstein H., Krook D., H Nair K., Pietrzak P. - Devloping PHP Applications for IBM Data Servers. IBM, 2006.

[12] Pew Internet \& American Life Project. Survey, USA, 2006.

[13] Exploring key facts about business process management with IBM WebSphere software. IBM, 2007, USA.

[14] Krupa T., Ostrowska T. - Strategy of Informatization and Development of Database in Business Organizations [in] New challenges and old problems in enterprise management (ed. T. Krupa). WNT, Warszawa 2002.

[15] Kasprzak T. - Integracja i architektury systemów informacyjnych przedsiębiorstw. Uniwersytet Warszawski, Warszawa 2000. 